\title{
FT-IR Analysis of the Effects of Polymeric Additives on Epoxy Homopolymerization or Hydroxyl Exchanges
}

\author{
Eamor M. $\mathrm{WoO}^{\dagger}$ \\ Department of Chemical Engineering, National Cheng Kung University, \\ Tainan, Taiwan 701-01
}

(Received December 2, 1996)

\begin{abstract}
Effects of polymeric additives, bisphenol-A polycarbonate, polyetherimide, and poly(hydroxyl ether of bisphenol-A), in epoxy systems on the epoxide reactivities were examined. No hardeners were used in the polymer/epoxy mixtures to exclude complications from crosslinking cure reactions. The epoxy/polymer mixtures upon heating at several selected isothermal temperatures were investigated using FT-IR analysis. Similar rates of decrease in the epoxide absorbance peak intensity were observed, which suggests that the polymeric additives exert no effect on the epoxide conversion rate in the absence of any hardeners. However, the production of the hydroxy groups was influenced by PC, but not by the other polymers (poly(ether imide) or phenoxy) investigated. Exchange reactions between the pendant $-\mathrm{OH}$ of the epoxy with the carbonate of PC might be responsible.
\end{abstract}

KEY WORDS Epoxy / Hydroxyl Exchange / FT-IR / Poly(ether imide) / Polycarbonate / Phenoxy

With unique properties and wide range of variation in molecular structures and selection of hardening agents, thermosetting epoxy resins are versatile materials used in a wide variety of applications such as coatings, electronic encapsulants, adhesives, or advanced composites. To suit various end-use requirements, they are also commonly formulated with various thermoplastic polymers, rubbers, or sometimes with other thermosetting resins. Addition of thermoplastic linear-chain polymers into thermosetting epoxies introduces factors that might lead to dramatic changes in cure kinetics, network structure, and properties.

The bisphenol-A polycarbonate (PC)-modified epoxy system is an example. The network-forming tendency in the tetraglycidyl-4,4'-diaminodiphenylmethane (TGDDM)/PC mixtures subjected to heating was first qualitatively noted by the persistent presence of indissoluble residues as the heated solid was placed in the tetrahydrofuran (THF) or dichloromethane solvent. ${ }^{1}$ The mixtures after short times of reactions (at $177^{\circ} \mathrm{C}$ or higher) were almost completely soluble in the solvents. After certain time duration ( 50 min or longer), the heated epoxy/PC sample gradually became partially indissoluble in the solvent. Eventually, after extended heating times at $177^{\circ} \mathrm{C}$, the samples became totally indissoluble and remained intact in the solvent. A recent study ${ }^{1}$ completed at our laboratory shows that TGDDM/PC mixtures of various compositions cured with an aromatic amine (4,4'-diaminodiphenyl sulfone, DDS) result in a crosslinked network of molecular-scale homogeneity. By excluding DDS from the epoxy/PC mixture system used as a simplified model, our continuing studies using FT-IR ${ }^{2}$ and solid-state NMR,${ }^{3}$ respectively, show that chemical transreactions take place between the carbonyl group of PC and the epoxide group of TGDDM acting as a tertiary amine auto-catalyst. Even without a hardening agent, these reactions can lead to a branched or ultimately a crosslinked TGDDM-PC network. Similar chemical reactions have also been demonstrated to occur between PC and a difunctional epoxy resin (diglycidylether of bisphenol-A, DGEBA). ${ }^{4-6}$ Don and Bell ${ }^{7}$ reported similar results in their study on a DGEBA/PC system upon heating, which are in excellent agreement with our findings. Nishikubo et al. ${ }^{8}$ reported carboxylepoxy addition reaction in solution-synthesis of $p$-vinylbenzyl glycidyl ether (a vinyl epoxide monomer) and itaconic acid monomethyl ester (a vinyl acrylic acid-ester monomer) with the carboxyl-epoxy addition proceeding as a side reaction leading to crosslinking. Nishikubo $e t$ al.'s work proves that pendant carboxyl-epoxide addition reactions lead to crosslinking. This work summarizes mechanisms of polymer-epoxy interactions including some special cases such as carbonate-epoxide addition and carbonate-hydroxyl exchanges that might lead crosslinking.

With the only known exception of bisphenol-A polycarbonate, most polymeric additives, such as polysulfones, phenoxy, poly(ether imide), etc., introduced into epoxy/hardener systems upon cure normally result in a network of a multi-phase morphology consisting of respective polymer and epoxy phases. What are the differences in the networking schemes with or without presence of these polymeric additives in epoxies? By FT-IR analyses and by specifically excluding hardeners to prevent complicating cure reactions, the focus of this study was to investigate possible effects of commonly used polymeric additives on networking schemes of epoxies with the polymers. Effects of several commonly used polymeric additives on epoxy homopolymerization and/or hydroxyl exchanges were investigated.

\section{EXPERIMENTAL}

\section{Materials and Preparation}

Two different epoxies were used in this study. One was a difunctional epoxy, diglycidyl ether of bisphenol-A (DGEBA) (Epikote-828, Shell Corp.), with an epoxide equivalent weight of $187 \mathrm{~g}$, and the other was a tetrafunc-

\footnotetext{
${ }^{\dagger}$ Author to whom correspondence should be addressed (Fax: +886-6-234-4496).
} 
tional epoxy, tetraglycidyl-4,4'-diamino-diphenylmethane (TGDDM) (Ciba-Geigy MY-720). Several linear-chain polymers with special functional groups were used for forming binary mixtures with the epoxies. The phenoxy thermoplastic polymer used was poly(hydroxyl ether of bisphenol-A) (Union Carbide, PKHH, $M_{n}=20000$ $\left.25000 \mathrm{~g} \mathrm{~mol}^{-1}\right)$. Two grades of bisphenol-A polycarbonate (PC) were used: GE Lexan ${ }^{\circledR} \mathrm{H}-1130$ with $M_{w}=23000 \mathrm{~g} / \mathrm{mol}$, and GE Lexan ${ }^{\circledR} 141$ (PC-141), with $M_{w}=58000 \mathrm{~g} \mathrm{~mol}^{-1}$. The third polymer, poly(ether imide) (PEI), was a commercial resin (GE Ultem $\left.{ }^{\circledR}{ }_{-} 1010\right)$. The chemical structures of PEI and phenoxy are shown as following:

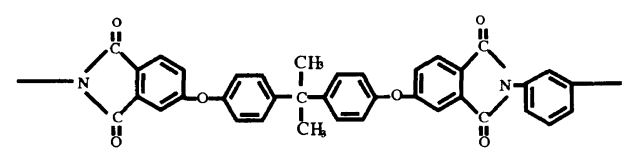

PEI<smiles>CC(C)CC(O)COc1ccc(C(C)(C)c2ccc(OC(C)(F)F)cc2)cc1</smiles>

Poly(hydroxyl ether of bisphenol-A) (phenoxy)

Amine or anhydride hardeners were intentionally rxcluded and not used for curing the epoxy/polymer mixtures since the aim of this study was to investigate possible interaction phenomena and chemical reactions between the polymer and epoxy molecules upon heating at high temperatures in typical cure conditions. Depending on composition, either melt-blending or solution-blending was used in preparation of polymer/epoxy samples. If the solution-blending method was used, the residual solvent (dichloromethane) in the sample mixtures was carefully driven off in a circulation oven with an exhaust fan at room temperature, followed by removal of residual solvent in a vacuum oven at $40^{\circ} \mathrm{C}$ for 48 hours or longer.

\section{Apparatus}

Fourier transform infrared spectra (FT-IR, Nicolet Magna-550) were obtained at $4 \mathrm{~cm}^{-1}$ resolution and averages were obtained from at least 64 scans in the standard wavenumber range of $400-4000 \mathrm{~cm}^{-1}$. IR was performed to identify changes of the functional groups in the molecular chains of the networking products. IR measurements were carried out either on thin films cast onto potassium bromide $(\mathrm{KBr})$ disk or by a powder mixing technique.

\section{RESULTS AND DISCUSSION}

Figure 1 shows the full spectrum for the TGDDM/PC $(10 / 1)$ samples subjected to $177^{\circ} \mathrm{C}$-heating for various times from 0 to $200 \mathrm{~min}$. The hydroxyl absorbance peak intensity is the smallest for the sample with no heating, indicating that a small amount of $-\mathrm{OH}$ probably was originally present in the system even without any heat-induced reactions. The hydroxyl peak becomes gradually pronounced in the samples heated for longer times, suggesting (1) homopolymerization among TGD-

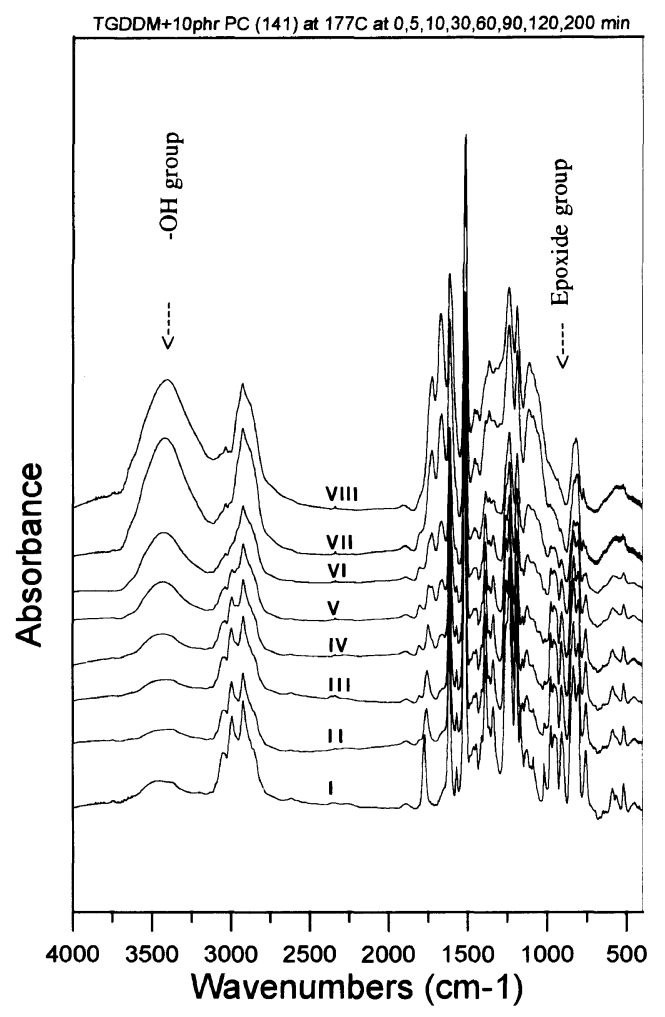

Figure 1. Full spectrum for TGDDM/PC (10/1) sample, $177^{\circ} \mathrm{C}$ heated for (I) 0 , (II) 5, (III) 10, (IV) 30, (V) 60, (VI) 90, (VII) 120, and (VIII) $200 \mathrm{~min}$.

DM producing epoxy oligomers with $-\mathrm{OH}$, or (2) isomerization of TGDDM molecules producing isomer products with hydroxyl groups. Note that both processes leading to generation of $-\mathrm{OH}$ also must involve ring-opening of the epoxide. It was experimentally verified that the neat TGDDM (with no PC or other polymers) upon heating, in absence of any hardeners, also produced $-\mathrm{OH}$ groups as evidenced by enhanced absorbance peak intensity (FT-IR spectra not shown for brevity). But does the presence of some specific functional groups in the polymers help to enhance or depress epoxide reactions leading to $-\mathrm{OH}$ groups, or do these polymeric additives exert no effects at all? A quantitative comparison will be made to clarify these points.

\section{Effects of Polymeric Additives on Epoxide Conversion}

To examine and compare the epoxide changes upon heating for samples of the neat epoxy or epoxy/polymer mixtures, the absorbance peaks at $907 \mathrm{~cm}^{-1}$ were enlarged and plotted on an offset axis. Figure 2 shows three sets of spectra of the epoxide absorbance at $907 \mathrm{~cm}^{-1}$ for (A) neat TGDDM, (B) TGDDM/PC $(4.7 \mathrm{wt} \%)$, and (C) TGDDM/PEI $(9.1 \mathrm{wt} \%)$, respectively, heated at $177^{\circ} \mathrm{C}$ for various times as labeled on the spectrum curves. Apparently, with or without polymers in the epoxy, the absorbance of the epoxide group steadily decreases in intensity upon heating. Furthermore, the decrease seems to be dependent only on heating time, and is quite unaffected by polymers added in the epoxy. Although it has been demonstrated that $\mathrm{PC}$ is capable of undergoing exchange reactions with the $-\mathrm{OH}$ group in epoxy, ${ }^{2}$ or similarly with the hydroxyl group of phenoxy, ${ }^{9,10}$ the presence of PC or PEI, as a 


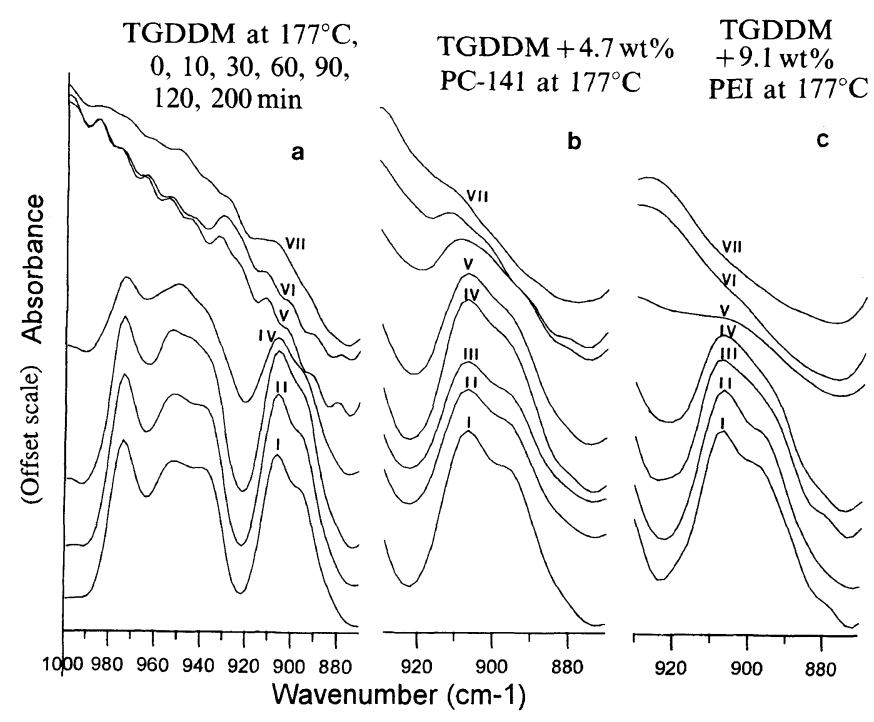

Figure 2. FT-IR spectra of epoxide absorbance at $907 \mathrm{~cm}^{-1}$ for (a) neat TGDDM, (b) TGDDM/PC (4.7wt $\%$ ), and (c) TGDDM/PEI $(9.1 \mathrm{wt} \%)$, respectively. Samples were heated at $177^{\circ} \mathrm{C}$ for (I) 0 , (II) 10, (III) 30, (IV) 60, (V) 90, (VI) 120, and (VII) $200 \mathrm{~min}$.

polymeric additive in the epoxy, causes no higher rates of decrease of the epoxide absorbance than those for the neat TGDDM with no additives. Clearly, the epoxide ring opening in TGDDM is not much affected by the presence of polymers.

To make a quantitative comparison, the decrease of the epoxide group absorbance peak $\left(907 \mathrm{~cm}^{-1}\right)$ normalized by the unchanged aromatic $\mathrm{C}-\mathrm{C}$ absorbance at $1615 \mathrm{~cm}^{-1}$ for the neat TGDDM and TGDDM/polymer mixtures was directly compared. Figure 3 shows that the normalized epoxide absorbance peak intensity is plotted as a function of heating time for the neat TGDDM and its mixtures with $9.1 \mathrm{wt} \%$ of PC. Note that two different grades of PC (with difference in molecular weights) were used in two separate series of experiments for confirmation and check of consistency. The figure shows that the neat TGDDM and TGDDM/PC mixtures all exhibit similar rates of decrease in epoxide absorbance peak intensity.

Similarly, the TGDDM epoxy mixtures with another polymer, phenoxy, were examined and compared with the neat epoxy. Figure 4 shows that the normalized epoxide absorbance peak intensity is plotted as a function of heating time for neat TGDDM and it mixtures with 4.7 and $9.1 \mathrm{wt} \%$ of phenoxy, respectively. Alternatively, plots showing the conversion may be more convincing. The fractional conversion at time $t$ was calculated according to $x(t)=\left(A_{0}^{\prime}-A_{t}^{\prime}\right) / A_{0}^{\prime}$, where $A^{\prime}$ indicates the normalized absorbance intensity and subscripts 0 and $t$ indicate the time. For brevity, conversion-time plots are not shown, but the results showed that the neat TGDDM and the TGDDM/phenoxy mixtures again exhibited similar rates of decrease in the epoxide absorbance peak intensity.

In Figure 5, the conversion of the epoxide groups is plotted as a function of heating time for neat TGDDM and its mixtures with various polymers as additives, containing the same $4.7 \mathrm{wt} \%$ polymer loading in all the mixtures. The fractional conversion at time $t$ was calculated in the same way as that for the previous figure.

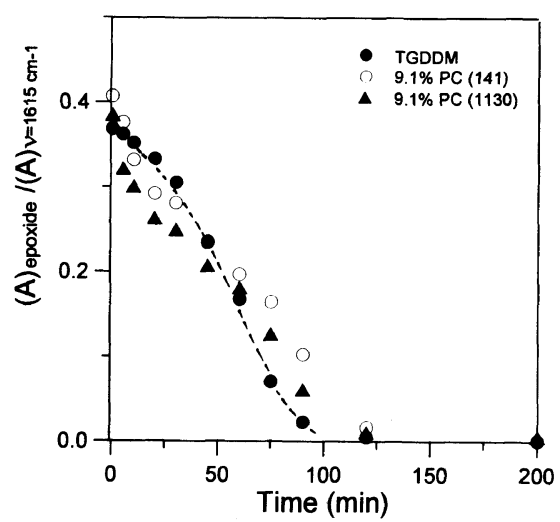

Figure 3. Normalized epoxide FT-IR peak intensity as a function of heating time for (O) TGDDM, (O) TGDDM/PC-141 (9.1 wt\%), and (A) TGDDM/PC-1130 (9.1 wt \%).

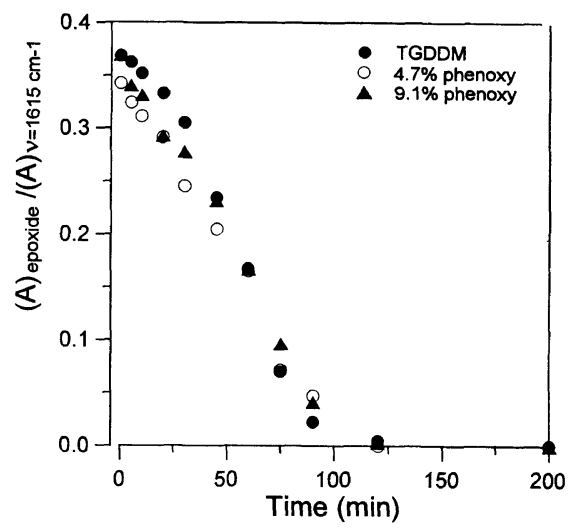

Figure 4. Normalized epoxide FT-IR peak intensity as a function of heating time. (๑) neat TGDDM, TGDDM/phenoxy mixtures with (O) $4.7 \mathrm{wt} \%$, and $(\boldsymbol{\Delta}) 9.1 \mathrm{wt} \%$ of phenoxy.

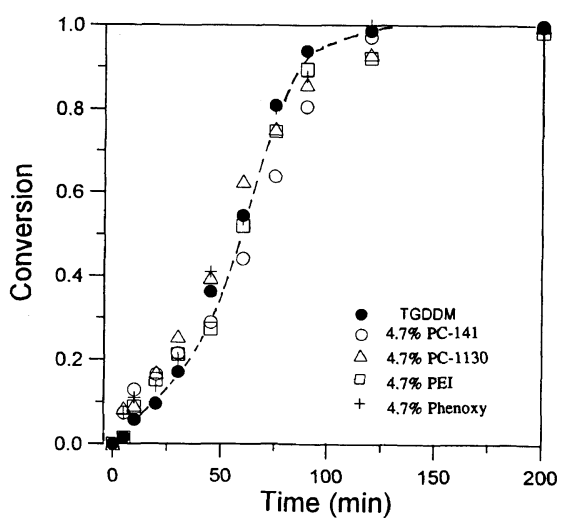

Figure 5. Conversion of epoxide group plotted as a function of heating time for ( ) neat TGDDM, (○) TGDDM/PC-141 (4.7 wt \%), $(\triangle)$ TGDDM/PC-1130 (4.7 wt \%), ( $\square$ ) TGDDM/PEI (4.7 wt \%), and $(+)$ TGDDM/phenoxy $(4.7 \mathrm{wt} \%)$.

A direct comparison in this figure shows all samples exhibited similar rates of decrease in the epoxide absorbance peak intensity, suggesting that the polymeric additives exerted no effect on the epoxide conversion rate.

Interestingly, the DGEBA epoxy was found to exhibit relatively unchanged intensity of the $-\mathrm{OH}$ absorbance peak upon heating. This suggests that the more pronounced change in the $-\mathrm{OH}$ peaks intensity upon heating of the TGDDM epoxy might be due to chemical structure. The structure of the TGDDM molecule itself 
is not only an epoxide but also a tertiary amine $\left(\mathrm{NR}_{3}\right)$, which is capable of self-catalyzing the reactions leading to oligomerization or homo-polymerization. Such a tertiary amino structure is not found in DGEBA.

\section{Effect of Polymers on Hydroxyl Group Generation}

There was ample evidence in the literature that chain extension can occur between epoxide and hydroxyl groups in most epoxies. Some amounts of initial hydroxyl groups in the epoxy might make it easier for homopolymerization to occur. The initiating hydroxyl groups may come from impurities as epoxy oligomers/isomers or trace moisture absorbed in the bulk of epoxy. Especially, this reaction can be more easily initiated in the presence of a tertiary amine. ${ }^{11-13}$ The following scheme illustrates how trace hydroxyl-containing species aided with a tertiary amine may lead to epoxy homopolymerization or isomerization with generation of more$\mathrm{OH}$ groups upon exposure to high temperatures:

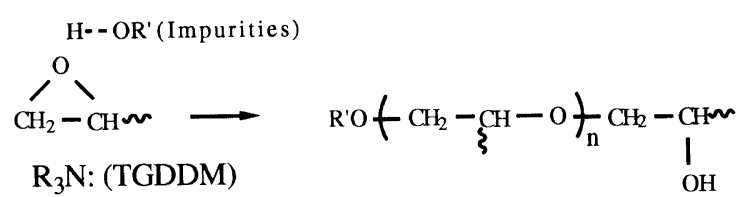

Alternatively, at high enough temperatures, epoxy isomerization may also proceed with consumption of epoxide groups, producing low-molecular-weight species containing hydroxyl groups ${ }^{13}$ :

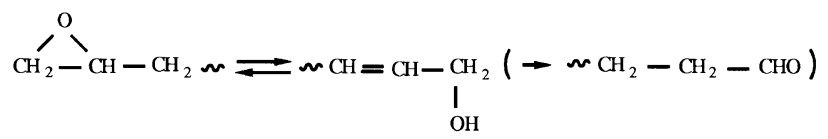

For some epoxies (such as TGDDM) that contain minimum hydroxyl groups, initial heat-induced reactions may still proceed, which lead to generation of more -OH groups in the epoxy segments at high enough temperatures according to several proposed mechanisms. ${ }^{2,9,10}$ The two possibilities for generation of hydroxyl groups in the neat TGDDM or TGDDM/polymer mixtures are represented in eq 1 and 2, respectively. Once the hydroxyl group is produced from epoxide ring opening, it stays with the epoxy oligomers or isomers until occurrence of hydroxyl exchange reactions between the epoxy and the polymeric additives. It has been proved that several types of exchange reactions take place between the hydroxyl group of epoxy and the carbonate group of PC such as the following ${ }^{14}$ :
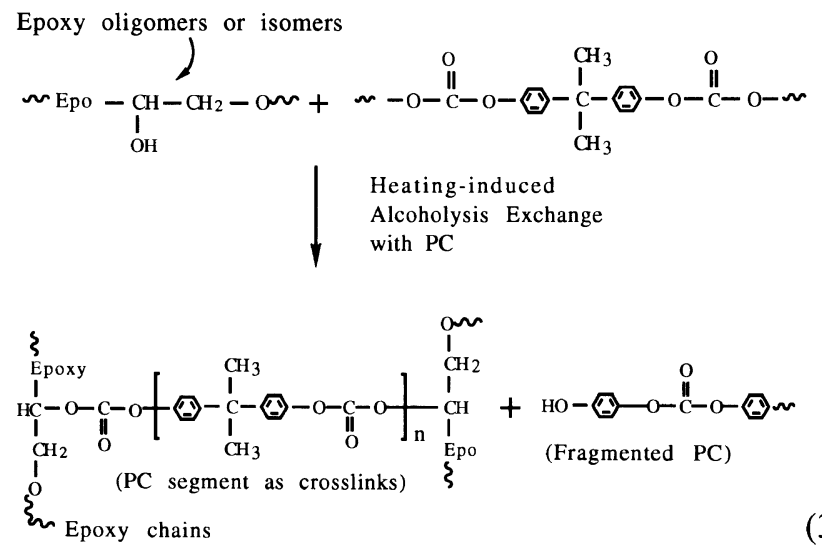

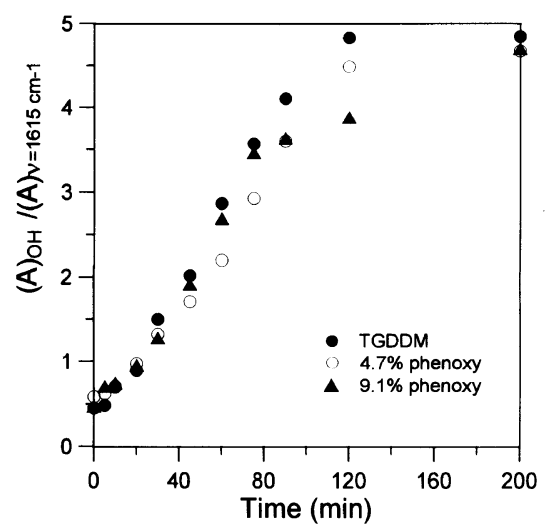

Figure 6. Plots of normalized IR peak intensity of hydroxyl group as a function of heating time for (O) TGDDM, (O) TGDDM/phenoxy $(4.7 \mathrm{wt} \%)$, and (A) TGDDM/phenoxy $(9.1 \mathrm{wt} \%)$.

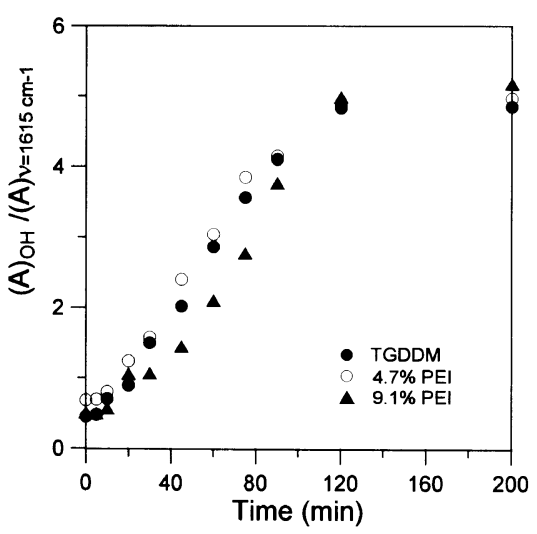

Figure 7. Normalized IR absorbance peak intensity of the hydroxyl group for epoxy/PEI samples: (O) TGDDM, (O) TGDDM/PEI (4.7 wt $\%$ ), and (A) TGDDM/PEI $(4.7 \mathrm{wt} \%)$ as a function of time at $177^{\circ} \mathrm{C}$.

Equation 3 proceeds only in the epoxy mixtures containing PC, but not in the neat epoxy or epoxy mixtures with other polymeric additives. Note that the above reaction leads initially to epoxy chains of homo-polymerized TGDDM molecules, which in turn are inter-connected with $\mathrm{PC}$ to eventually form a network. ${ }^{2}$ The hydroxyl groups are not consumed but only exchanged between the epoxy and the PC chains. Several previous studies demonstrate that transreactions and/or alcoholysis (between PC carbonate group and epoxy hydroxyl group) lead to increasingly greater extents of aliphatic linkages with the carbonate group (i.e., $\mathrm{C}-\mathrm{O}-\mathrm{CO}-\mathrm{O}-\mathrm{C}$ ), which causes a downshift of the carbonyl IR absorption peak. ${ }^{2,3}$

Figure 6 shows plots of the normalized FT-IR absorbance peak intensity of the hydroxyl group $\left(3500 \mathrm{~cm}^{-1}\right)$ for the samples of the neat TGDDM, the TGDDM/phenoxy (4.7 wt \%), and TGDDM/phenoxy $(9.1 \mathrm{wt} \%)$ heated at $177^{\circ} \mathrm{C}$ for various time from 0 to $200 \mathrm{~min}$. The trend of variation of the hydroxyl absorbance peak with respect to heating time appears to be the same for all samples. That is, the presence of phenoxy in the epoxy does not exert any effect on the rate of epoxide reaction leading to production of the -OH group.

The effects of another polymeric additive, PEI, were also examined for comparison. Figure 7 shows plots of the normalized FT-IR absorbance peak intensity of the hydroxyl group $\left(3500 \mathrm{~cm}^{-1}\right)$ for samples of neat 


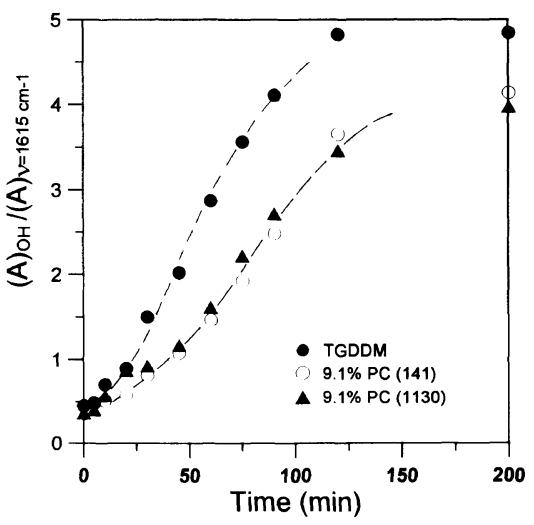

Figure 8. Hydroxyl group absorbance intensity for epoxy/PC samples: () TGDDM, (O) TGDDM/PC-141 (9.1 wt\%), and (A) TGDDM/PC-1130 $(9.1 \mathrm{wt} \%)$ as a function of time at $177^{\circ} \mathrm{C}$.

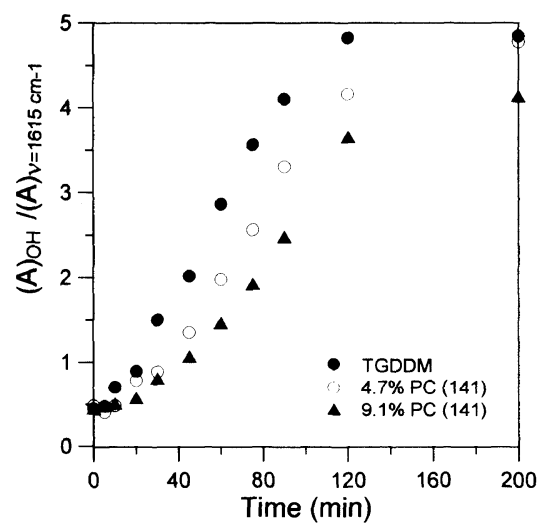

Figure 9. Hydroxyl group absorbance intensity for epoxy/PC samples: () TGDDM, (O) TGDDM/PC-141 (4.7wt \%), and (A) TGDDM/PC-141 $(9.1 \mathrm{wt} \%)$ as a function of time at $177^{\circ} \mathrm{C}$.

TGDDM, TGDDM/PEI (4.7 wt \%), and TGDDM/PEI $(9.1 \mathrm{wt} \%)$ heated at $177^{\circ} \mathrm{C}$ for various times from 0 to $200 \mathrm{~min}$. For shorter times of heating, there is some difference. However, for longer heating times, variation of the hydroxyl absorbance peak with respect to heating time appears to be the same for all samples. That is, PEI in the epoxy exerts no significant effect on the rate of production of $-\mathrm{OH}$ groups from epoxide reactions.

Variation of the hydroxyl peak for the TGDDM/PC mixtures was found to be different from that of the neat TGDDM upon heating. Figure 8 shows plots of the normalized FT-IR absorbance peak intensity of the hydroxyl group for the samples of neat TGDDM, TGDDM/PC-141 (9.1 wt \%), and TGDDM/PC-1130 $(9.1 \mathrm{wt} \%)$ heated at $177^{\circ} \mathrm{C}$ for various times from 0 to 200 min. Again, two different grades of the PC polymer were used to check consistency. The normalized hydroxyl absorbance peak intensity for the two TGDDM/PC mixture samples is consistently lower than that for the neat TGDDM sample upon heating. That is, $\mathrm{PC}$ in the epoxy exerts a significant effect to depress generation of -OH groups.

The content of PC was varied in the TGDDM/PC mixtures and the effects were compared. Figure 9 shows plots of the normalized FT-IR absorbance peak intensity of the hydroxyl group for samples of neat TGDDM, TGDDM/PC-141 (4.7 wt \%), and TGDDM/PC-141 $(9.1 \mathrm{wt} \%)$ heated for various times from 0 to $200 \mathrm{~min}$.
The normalized hydroxyl absorbance peak intensity for the TGDDM/PC mixture samples is consistently lower than that for the neat TGDDM sample upon heating and the difference is apparently larger for TGDDM/PC with higher PC contents. This again shows that PC in the epoxy exerts significant effect on production $-\mathrm{OH}$ groups from epoxide reactions.

However, the results in Figure 5 do not suggest that the epoxide conversion was affected by the presence of PC in the epoxy. It is not unreasonable to assume that the observed generation of the hydroxyl group (i.e., increased absorbance peak intensity) entirely comes from epoxide conversion (to oligomers or isomers). If the epoxide conversion is not affected by PC, then why would the rate of $-\mathrm{OH}$ generation be influenced by $\mathrm{PC}$ ? As stated earlier, neither PEI nor phenoxy possesses functional groups capable of undergoing exchange reactions with the $-\mathrm{OH}$ groups of the epoxy. Thus, PEI or phenoxy expectedly did not influence the peak intensity of the hydroxyl group upon heating of the polymer/epoxy mixture. Hydroxyl exchange occurs between the carbonate group of PC and hydroxyl group of epoxy to displace the pendant $-\mathrm{OH}$ of the epoxy with a carbonate linkage, as shown earlier in eq. 3. Although the $-\mathrm{OH}$ groups are conserved before and after the exchange, the -OH groups displaced from the networking epoxy chains might be attached to smaller-molecule products, which can be driven off upon heating. Thus, these exchange reactions might have led to lower rates of increase in hydroxyl absorbance peak intensity. Weight measurements before and after isothermal heating were performed on the epoxy/PC samples of $0,4.7$, and 9.1 wt $\%$ PC. There was some weight loss, and the samples with higher PC contents showed slightly higher loss. Increasing hydrogen bonding in the PC-epoxy pair may be partially responsible for the relatively slower increase of $-\mathrm{OH}$ intensity for the epoxy/PC sample with a higher PC content.

\section{CONCLUSION}

Epoxy/polymer mixtures upon heating at selected isothermal temperatures were investigated using FT-IR analysis. The IR absorbance intensities of the epoxide and hydroxyl groups were monitored as a function of time. Similar rates of decrease in the epoxide absorbance peak intensity was observed, which suggests that the polymeric additives (PC, PEI, phenoxy) exert no effect on the epoxide conversion rate in the absence of any hardeners.

Increased hydroxyl absorbance intensity was observed in neat TGDDM or TGDDM/polymer mixtures upon heating. The hydroxyl groups came from conversion of the epoxide groups in two different forms: isomerization or homopolymerization. In comparison with the TGDDM epoxy systems which exhibited increasing $-\mathrm{OH}$ intensity, the DGEBA epoxy was found to exhibit relatively unchanged intensity of $-\mathrm{OH}$ absorbance peak upon heating. The tertiary amine $\left(\mathrm{NR}_{3}\right)$ structure in TGDDM, but absent in DGEBA, might have accelerated the reactions leading to the observed changes.

The presence of phenoxy or PEI in the epoxy does not exert any effect on production of the $-\mathrm{OH}$ group. 
PC in the epoxy exerts a significant effect on the number of $-\mathrm{OH}$ groups from epoxide reactions. If the epoxide conversion is not affected by $\mathrm{PC}$, then why would the rate of $-\mathrm{OH}$ generation be influenced by $\mathrm{PC}$ ? This may be related to the fact that neither PEI nor phenoxy possesses functional groups that are capable of undergoing exchange reactions with the $-\mathrm{OH}$ groups of the epoxy produced from homopolymerization or isomerization. The exchange reaction between the pendant $-\mathrm{OH}$ of the epoxy with a carbonate linkage might have led to lower rates of increase in hydroxyl absorbance peak intensity.

Acknowledgment. Technical assistance provided by Dr. C. C. Su in performing the FT-IR experiments is appreciated. The author is indebted to the research grants in related series \#NSC 85-2216-E006-006 and NSC862216-E006-007 kindly provided by the National Science Council.

\section{REFERENCES}

1. C. C. Su, J.-F. Kuo, and E. M. Woo, J. Polym. Sci., Polym. Phys., 33, 2235 (1995).

2. C. C. Su and E. M. Woo, Macromolecules, 28, 6779 (1995).

3. C. C. Su, E. M. Woo, C.-Y. Chen, and R. R. Wu, Polymer, to appear.

4. M. Abbate, E. Martuscelli, P. Musto, G. Ragosta, and G. Scarinzi, J. Polym. Sci., Polym. Phys., 32, 395 (1994).

5. E. M. Woo and M. N. Wu, Polymer, 37, 2485 (1996).

6. M. N. Wu and E. M. Woo, J. Polym. Sci., Polym. Phys., 34, 789 (1996).

7. T.-M. Don and J. P. Bell, J. Polym. Sci., Polym. Chem., 34, 2103 (1996).

8. T. Shimokawa, Y. Shinmoto, A. Kameyama, T. Nishikubo, J. Polym. Sci., Polym. Chem., 34, 1951 (1996).

9. X. Yang, P. C. Painter, and M. M. Coleman, Macromolecules, 25, 4996 (1992).

10. E. M. Woo and S. N. Yau, J. Polym. Sci., Polym. Chem. Ed., 35, 97 (1997).

11. H. Lee and K. Neville, "Handbook of Epoxy Resins," McGraw-Hill Book Company, New York, N.Y., 1984, Chapter 5.

12. C. C. Price and D. D. Carmelite, J. Am. Chem. Soc., 88, 4039 (1966).

13. A. J. Attias, B. Bloch, and F. Laupretre, J. Polym. Sci., Polym. Chem., 28, 3445 (1990).

14. E. M. Woo and C. C. Su, Polym. J., 29, 514 (1997). 